\title{
Fine Line Luminescence and Raman Spectra of Distorted Forms of Metalloporphyrins: Pt-Porphine
}

\author{
Aleksander S. Starukhin ${ }^{\circledR}$ and Mikalai M. Kruk \\ B.I. Stepanov Institute of Physics of National Academy of Sciences, Minsk, 220072, Belarus \\ Corresponding authorE-mail: astar@imaph.bas-net.by
}

\begin{abstract}
Phosphorescence spectra, phosphorescence excitation spectra and Resonance Raman spectra were measured for Pt-porphine in solid matrices at cryogenic temperatures, as well as in solution at room temperature. In phosphorescence spectra of Pt-porphine the manifestations of the two forms in the ground state were revealed. The frequencies of normal vibrational modes in the ground electronic state were measured separately for both forms. Analysis of the differences in the normal mode frequencies for two macrocycle conformations and comparison with the normal mode frequencies in Resonance Raman spectra resulted to assignment of these spectral forms to corresponding macrocycle distortion types.
\end{abstract}

Keywords: Pt-porphine, $n$-alkanes matrices, highly-resolved phosphorescent spectra, Raman spectra, nonplanar distortion, macrocycle conformations.

\section{Introduction}

Metallocomplexes of porphyrins attract the great interest as perspective materials for use in various scientific and industrial applications. In particular, metal complexes of porphyrins with $\mathrm{Pd}^{\mathrm{II}}$ and $\mathrm{Pt}^{\mathrm{II}}$ ions are considered as epy base compounds in design of organic optical light emitting diodes. ${ }^{[1,2}$ and Refs. therein] Spectral parameters of organometallic complexes are very important for practical applications, and the character of their transformation under incorporation into different media, as well as upon variation of temperature, pressure, etc. is of great significance.

Firstly, spectral manifestation of two spectral forms were detected in unresolved phosphorescence spectra of $\mathrm{Pd}$ porphine $(\mathrm{PdP})$ at $77 \mathrm{~K}$, and the form shifted in long-wavelength region was attributed to distorted molecular structure with the position of $\mathrm{Pd}^{\mathrm{II}}$ ion out of plane of the porphyrins macrocycle. ${ }^{[3]}$ Later, the occurrence of two conformations of $\mathrm{PdP}$ in the ground electronic state at $77 \mathrm{~K}$ was proved, ${ }^{[4]}$ however, the authors were not correct in the estimation of the type of the macrocycle distortion, because highly resolved spectra were not available to be recorded at $77 \mathrm{~K}$. Data about distorted forms of Pt-porphine (PtP) in unresolved spectra have not been reported so far.

Recently, we detected highly resolved spectra of PdP in $n$-alkane matrices at liquid helium temperatures, and two types of distorted forms of metalloporphyrins were found. ${ }^{[5,6]}$ For both forms selectively excited phosphorescence and phosphorescence excitation spectra were recorded. It allowed proving the spectral manifestation of the two forms in the ground state. Short-wavelength spectral form is attributed to the structure, where the porphyrin macrocycle is planar, while long-wavelength form is associated with the nonplanar saddle-type conformation of PdP. The frequencies of the normal vibrations in the ground electronic state were measured separately for the both forms and the differences in the normal modes of two macrocycle conformations allowed us to attribute these spectral forms to particular distortion types.

Distorted forms of metallocomplexes of porphine with $\mathrm{Mg}^{\mathrm{II}}$ and $\mathrm{Zn}^{\mathrm{II}}$ ions were discussed in details. ${ }^{[7]}$ It was shown that in these cases the formation of distorted forms has essentially more complicated spectral manifestations.

Here we report on highly resolved phosphorescence spectra of Pt-porphine (PtP) in solid $n$-alkane matrices at liquid helium temperature and Raman spectra of PtP at ambient temperature. The influence of matrix on stabilization and spectral shift of the planar and distorted molecular conformations of PtP is discussed.

\section{Experimental}

PtP was synthesized from the free base porphine (Frontier Scientific, Inc.) according to standard procedure. ${ }^{[3]}$

The compound was purified chromatographically on aluminium oxide. The identity of the structure was checked
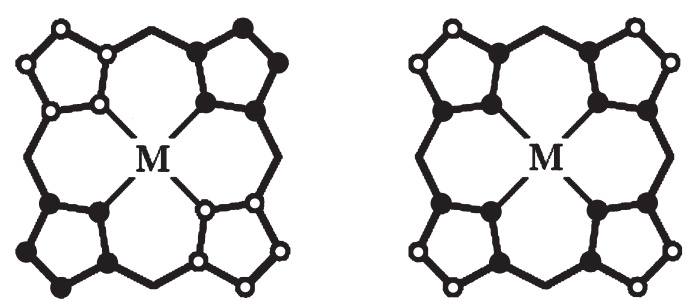

Figure 1. The structure of studied metalloporphines: $\mathrm{M}=\mathrm{Pt}$. In the saddle conformation (left panel) the pairs of oppositely located pyrrole rings are under and above the porphyrin macrocycle mean plane (denoted with open and closed circles, respectively) and the meso carbons $\mathrm{C}_{m}$ are in the plane. The metal ion is in the plane. In the dome conformation (right panel) all of the $\mathrm{C}_{\mathrm{b}}$ carbons are on one side (under) of the porphyrin macrocycle mean plane, the meso carbons are in (or near) the plane, and the $\mathrm{C}_{\mathrm{a}}$ carbons and the nitrogens are above the plane. The metal ion is above the plane at the top of this dome structure. 
by spectroscopic methods and was found to correspond to the literature data. ${ }^{[3]}$ Dilute solutions of PtP in $n$-hexane, $n$-heptane, $n$-octane, $n$-nonane and $n$-decane (Fluka, spectroscopic grade) were cooled in liquid helium $(4.2 \mathrm{~K})$ or in a bath of liquid helium pumped down to temperature $1.2 \mathrm{~K}$. To minimize concentration and aggregation effects we used the samples of Pt-porphine with $\sim 10^{-6} \mathrm{M}$ concentrations.

Luminescence was excited by the radiation of UV and visible lines from Coherent Innova $90 \mathrm{Ar}^{+}$laser and dispersed by Spex 1404 double monochromator. The signal was recorded with a cooled photomultiplier tube (Hamamatsu, type R-943-2) and the home-build photon counting system. All emission spectra were corrected for spectral sensitivity with using the radiation of a tungsten lamp (Osram WI-14). The dye laser (Lambda Physic FL-2000, modified to a spectral resolution of $0.15 \mathrm{~cm}^{-1}$ by Radiant Dyes) was used for selective excitation of phosphorescence spectra and for phosphorescence excitation spectra. It was pumped by the third harmonic of Nd-YAG laser (Spectron Laser Systems SL803 , wavelength is $354 \mathrm{~nm}$, pulse width $\sim 12 \mathrm{~ns}$, repetition rate $20 \mathrm{~Hz}$ ). Phosphorescence spectra were measured with home-built luminescent spectrometer based on DFS-24 monochromator as well. ${ }^{[8]}$ Phosphorescence was excited by either second harmonic of Nd-YAG laser LS-2115 (LOTIS-TII), Nd-YAG pumped tunable dye laser or UV emitting diode NCCU001E (Nichia, $\lambda_{\text {peak }}=385$ $\mathrm{nm}, \Delta \lambda=20.0 \mathrm{~nm}$ ). The signal was recorded with two-channel oscilloscope unit BORDO 220 which was integrated into the spectral data acquisition complex Helios-1.43.

Raman spectra were detected with the use of "Spectra Pro 500i" Raman spectrometer. Spectra were excited by radiation of second harmonic $(\lambda=532 \mathrm{~nm}$, power $25 \mathrm{~mW})$ Nd-YAG laser (Crystal laser Model GCL-025-S).

Phosphorescence spectra of PtP were measured in the wide range of excitation power both with pulsed and CW lasers. All the spectra have the same shape and structure. This fact indicates that no photochemistry takes place.

\section{Results and Discussion}

Phosphorescence spectra of PtP in $n$-octane at $4.2 \mathrm{~K}$ are shown in Figure 2. Under non-selective ultraviolet excitation (Figure 2a) we detected a well resolved spectrum of phosphorescence for PtP, similar to that of PdP. However, the interpretation of this spectrum is complicated by overlapping of wide set of lines. It was suggested that it is due to coexistence of two spectra. To check this assumption we recorded the phosphorescence excitation spectra under excitation in the $\mathrm{S}_{0} \rightarrow \mathrm{S}_{1}$ channel and detection at 16276 and $16312 \mathrm{~cm}^{-1}$ (Figure $3)$. Figures $3 \mathrm{a}$ and $3 \mathrm{~b}$ show, that the two types of centers are manifested in the range of $\mathrm{S}_{0} \rightarrow \mathrm{S}_{1}$ transition with the splitting of 16 and $29 \mathrm{~cm}^{-1}$, correspondingly. In analogy with situation for PdP we marked a short-wavelength spectral form as Form 0 (F0) and a long-wavelength form as Form I (FI). Figure 2 demonstrates distinct differences for relative intensities of the 0-0 line and vibrational transitions in the phosphorescence spectra of these two forms. Very weak intensity of 0-0 transition for phosphorescence spectra of the F0 form may be due to strongly forbidden character of the $\mathrm{T}_{1} \rightarrow \mathrm{S}_{0}$ electronic transition for planar form $\left(\mathrm{D}_{4 \mathrm{~h}}\right.$ type of symmetry).

We have tried to obtain the selective excitation of individual forms in the range of the $\mathrm{S}_{0} \rightarrow \mathrm{S}_{1}$ transition (excitation in lines at 19277 and $19312 \mathrm{~cm}^{-1}$ ), correspondingly (Figure 2b,c). For the Form 1 we have detected a practically individual spectrum (Figure 2b). The situation about spectral detection for the form F0 is not so simple. The strong overlapping of the broadened lines (as compared with those for PdP) corresponding to the $\mathrm{S}_{0} \rightarrow \mathrm{S}_{1}$ transitions for the both forms prevents the detection of spectrum for $\mathbf{F 0}$ form individually. Figure $2 \mathrm{c}$ has the character similar to that for the superposition of phosphorescence from the both forms (Figure $2 \mathrm{a}$ ). Thermally activated peaks at $4.2 \mathrm{~K}$ with the splitting of about $15 \mathrm{~cm}^{-1}$ could give rise to additional difficulties for the interpretation of these spectra. ${ }^{[8]}$

The F0 and FI forms with positions of the 0-0 transitions split by $18 \mathrm{~cm}^{-1}$ in $n$-octane $\left(11 \mathrm{~cm}^{-1}\right.$ in $n$-heptane, $50 \mathrm{~cm}^{-1}$ in $n$-nonane and $36 \mathrm{~cm}^{-1}$ in $n$-decane) we assign to the spectral manifestation of two forms in the phosphorescence spectra of PtP, similar to PdP. These two spectral forms are attributed to different conformations of PtP which exist simultaneously as independent chromophore types in the frozen sample. Relatively small energy splitting (not more than $50 \mathrm{~cm}^{-1}$ ) as compared with that for the porphine metallocomplexes with $\mathrm{Mg}^{\mathrm{II}}, \mathrm{Zn}^{\mathrm{II}}$ and $\mathrm{Pd}^{\mathrm{II}}$ ions is likely to be due to the stronger interaction between $\mathrm{Pt}^{\mathrm{II}}$ ion and the porphine ligand for this compound. On our opinion, very small spectral splitting between two spectral forms (maximum $50 \mathrm{~cm}^{-1}$ in comparison with more than

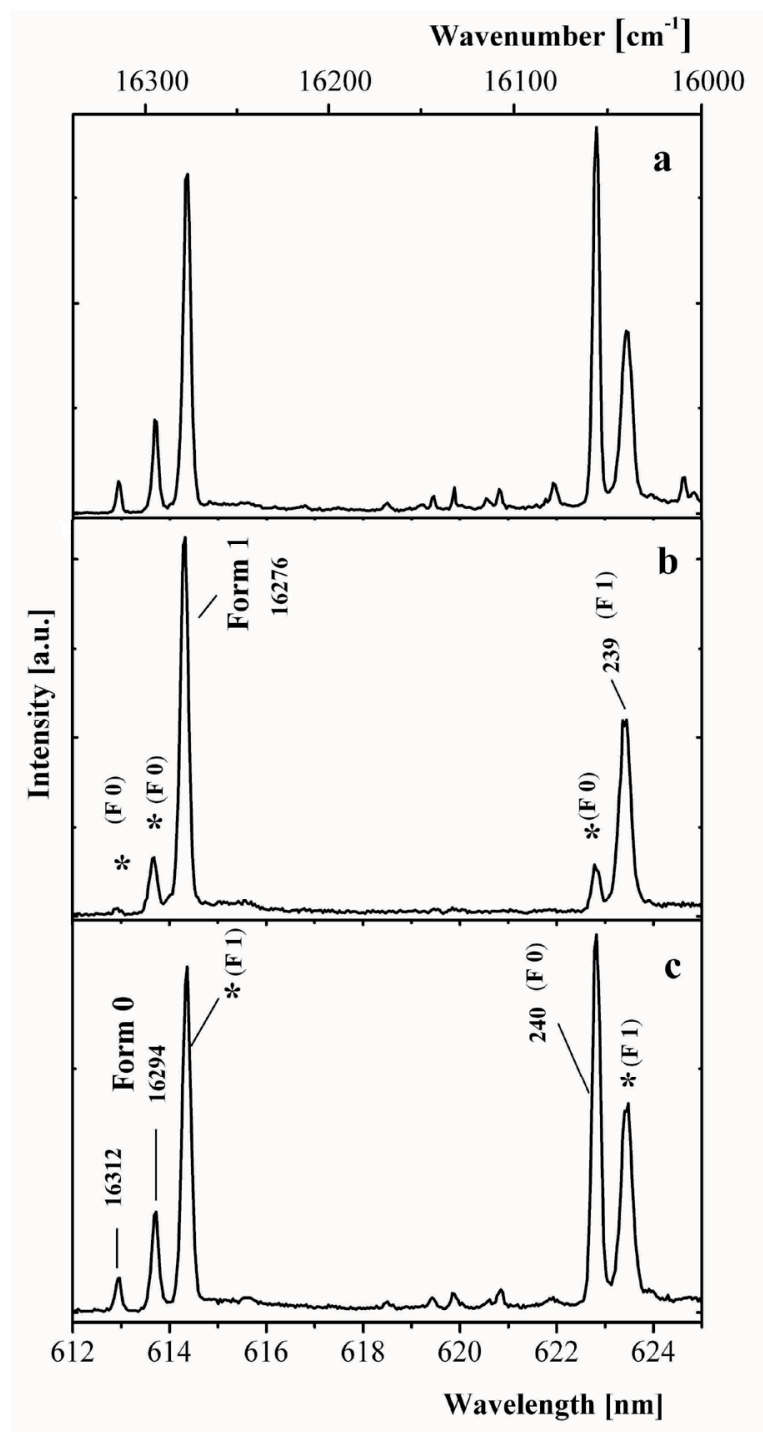

Figure 2. Phosphorescence spectra of PtP in n-octane under nonselective excitation with $363.8 \mathrm{~nm}$ line of $\mathrm{Ar}^{+}$laser (a) and under selective excitation with $\lambda_{\text {exc }}=518.75 \mathrm{~nm}(\mathrm{~b})$ and under excitation with $\lambda_{\text {exc }}=517.81 \mathrm{~nm}$ (c) at $4.2 \mathrm{~K}$. * - corresponds to the weak traces of the F0 and FI forms in the spectra of the FI and F0 forms. 


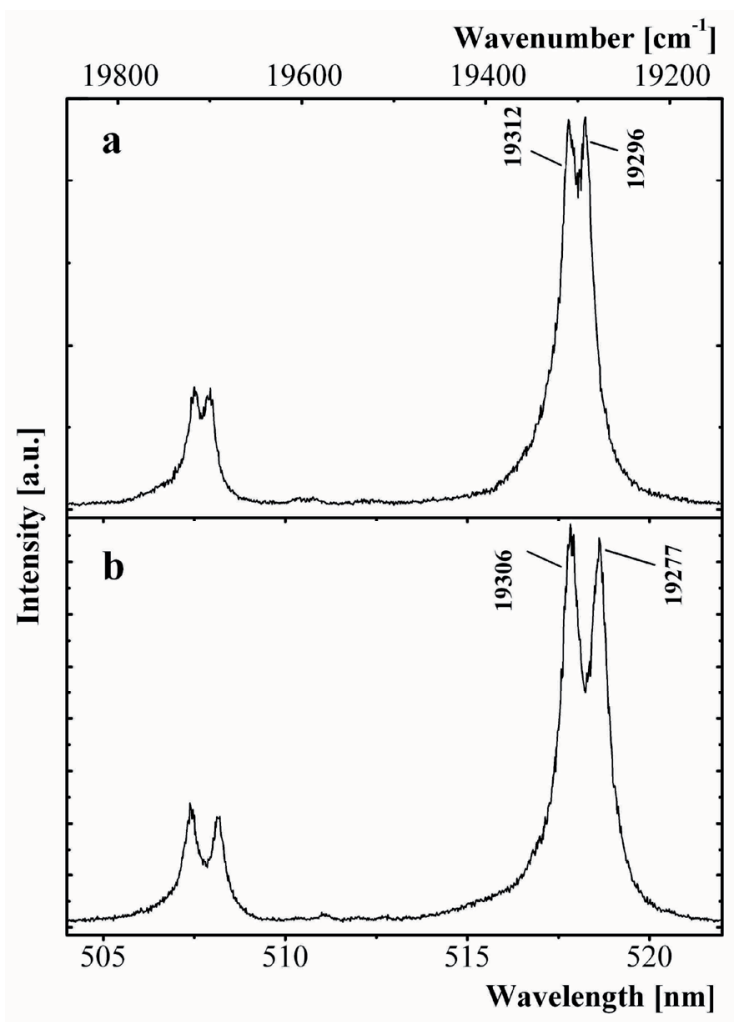

Figure 3. Phosphorescence excitation spectra (excitation in the $\mathrm{S}_{0} \rightarrow \mathrm{S}_{1}$ channel) for the two forms of PtP in $n$-octane under detection at $16312 \mathrm{~cm}^{-1}$ (a) and $16276 \mathrm{~cm}^{-1}$ (b) at $4.2 \mathrm{~K}$.

$100 \mathrm{~cm}^{-1}$ for PdP in $n$-nonane) gives no way to detect the different spectral forms in unresolved phosphorescent spectra at $77 \mathrm{~K}$.

Additional support of coexistence of two spectral forms of $\mathrm{PtP}$ in the solid matrices arises from phosphorescence time decay measurements. The phosphorescence decay curves demonstrate the clear difference between the lifetimes of the F0 and FI forms. The F0 form has biexponential decay with lifetimes 0.24 and $0.39 \mathrm{~ms}$, whereas the FI form has monoexponential decay with lifetime $0.29 \mathrm{~ms}$.

We have measured Resonance Raman spectrum (RRS) of $\mathrm{PtP}$ in $\mathrm{CS}_{2}$ at room temperature (at these conditions the PtP macrocycle is known to be planar ${ }^{[9,10]}$ ) and compared the set of normal mode frequencies with those of vibrations of the F0 and FI forms in solid matrix at $4.2 \mathrm{~K}$. The frequencies of the most intense modes in phosphorescence spectra of $\mathrm{PtP}$ at liquid helium temperature and in RRS for PtP at room temperature are presented in Table 1.

Table 1. Frequencies $\left(\mathrm{cm}^{-1}\right)$ of the PtP normal vibrations in Resonance Raman spectrum (RRS) and in phosphorescence spectra $(\mathrm{PhS})$.

\begin{tabular}{ccc}
\hline RRS & PhS F0 form in $n$-octane & PhS FI form in $n$-octane \\
\hline 1576 & 1569 & 1569 \\
1601 & 1606 & 1611 \\
1628 & 1629 & 1635 \\
\hline
\end{tabular}

The most pronounced difference in normal mode frequencies between F0 and FI conformations of PtP was observed forthe high frequency modes, like it was in the cases we have proved earlier for porphine complexes with $\mathrm{Mg}^{\mathrm{II}}, \mathrm{Zn}^{\mathrm{II}}$ and $\mathrm{Pd}^{\mathrm{II}}$ ions. These normal modes have the greatest contributions from the $\mathrm{C}_{\mathrm{a}} \mathrm{C}_{m}$ stretching vibrations (up to 95\%) as is evident from the results of normal coordinate analysis. ${ }^{\left[{ }^{[9]}\right.}$ In going from the F0 to FI forms the lines 1606 and $1629 \mathrm{~cm}^{-1}$ are shifted up by 5 and $6 \mathrm{~cm}^{-1}$, correspondingly. Comparison of RRS and PhS data indicate that frequencies of the F0 form and RRS are essentially closer than those of the FI form and RRS. This fact gives again the evidences that F0 form belongs to the planar macrocycle conformation. The $\mathrm{C}_{\mathrm{a}}-\mathrm{C}_{m}$ bonds should have the largest perturbations upon saddle-type distortion. Similar behaviour of these normal modes for the planar and the saddle-type conformations of $\mathrm{MgP}, \mathrm{ZnP}$ and PdP complexes was observed in highly-resolved spectra. ${ }^{[7]}$

\section{Conclusions}

The highly resolved phosphorescence and excitation of phosphorescence spectra were measured separately for the planar and the saddle-type conformers of PtP and the differences between two conformations were discussed. The results demonstrate that selective laser spectroscopy in combination with matrix isolation technique is a very promising tool for the studies of different nonplanar conformations of metalloporphyrins at low temperatures.

Acknowledgments. This work was supported by the Foundation for Fundamental Research of the Republic of Belarus (project Ch08R-033).

\section{References}

1. Baldo M.A., O’Brien D.F., You Y., Shoustikov A., Sibley S., Tompson M.E., Forrest S.R. Nature (London) 1998, 395, 151154.

2. Brooks J., Babayan Y., Lamansky S., Djurovich P.I., Tsuba I., Bau R., Tompson M.E. Inorganic Chemistry 2002, 41, 30563061.

3. Eastwood D.L., Gouterman M. J. Molecular Spectroscopy 1970, 35, 359-375.

4. Knyukshto V.N., Shul'ga A.M., Sagun E.I., Zen'kevich E.I. Optics and Spectroscopy 2002, 92, 53-62.

5. Starukhin A., Kruk M., Czerwieniec R. J. Luminescence 2008, 128, 531-536.

6. Starukhin A., Kruk M. Optics and Spectroscopy 2007, 103, 317-322.

7. Starukhin A.S., Shulga A.M. Optics and Spectroscopy 2005, 98, 780-785.

8. Kruk M.M., Starukhin A.S., Czerwieniec R. J. Porphyrins Phthalocyanines 2008, 12, 1201-1210.

9. Solovyov K.N., Gladkov L.L., Gradyushko A.T., Ksenofontova N.M., Starukhin A.S. J. Molecular Structure 1978, 45, 267-305.

10. Verma A.L., Bernstein H.J. J. Chem. Phys. 1974, 61, 25602565. 